\title{
New probe microphone for investigating the acoustics of the ear
}

\author{
Lauridsen, Ole; Günthersen, Carsten
}

Published in:

Acoustical Society of America. Journal

Link to article, DOI:

$10.1121 / 1.385784$

Publication date:

1981

Document Version

Publisher's PDF, also known as Version of record

Link back to DTU Orbit

Citation (APA):

Lauridsen, O., \& Günthersen, C. (1981). New probe microphone for investigating the acoustics of the ear. Acoustical Society of America. Journal, 69(5), 1496-1498. https://doi.org/10.1121/1.385784

\section{General rights}

Copyright and moral rights for the publications made accessible in the public portal are retained by the authors and/or other copyright owners and it is a condition of accessing publications that users recognise and abide by the legal requirements associated with these rights.

- Users may download and print one copy of any publication from the public portal for the purpose of private study or research.

- You may not further distribute the material or use it for any profit-making activity or commercial gain

- You may freely distribute the URL identifying the publication in the public portal

If you believe that this document breaches copyright please contact us providing details, and we will remove access to the work immediately and investigate your claim 


\title{
New probe microphone for investigating the acoustics of the ear
}

\author{
Ole Lauridsen \\ Fonden for hjælpemidler til handikappede, Fortunstræde I, 1065 Copenhagen $K$, Denmark
}

\section{Carsten Günthersen}

The Acoustics Laboratory, Technical University of Denmark, Denmark

(Received 15 August 1980; accepted for publication 6 November 1980)

\begin{abstract}
A new probe microphone employing a soft tube and a compensation network for the tube response is described. Because of the soft tube, this microphone is especially suited for investigating the acoustics of the
\end{abstract} outer ear and the ear canal, and some such measurements are given.

PACS numbers: 43.88.Kb, 43.66.Yw

\section{INTRODUCTION}

To investigate the sound pressure in inaccessible places, probe microphones of ten have to be used. Available probe microphones have, until recently, employed rigid tubes, and for investigating the sound pressure response near the human eardrum, this has posed difficulties because the rigid tube can easily rupture the eardrum. In the following, a new probe microphone will be described employing a soft silicon-rubber tube which can be inserted into the human ear canal without damaging the skin or the eardrum.

\section{DESCRIPTION OF THE PROBE MICROPHONE}

For easy correction of the frequency response and for use in compressor loops, a smooth response is desired. This has previously been obtained by placing damping material inside the probe or using an exponential horn as probe. ${ }^{1}$

Another way of smoothing the response is to employ a system as described in Carlson, ${ }^{2}$ originally intended for use in the acoustical outlet in a hearing aid.

(a)

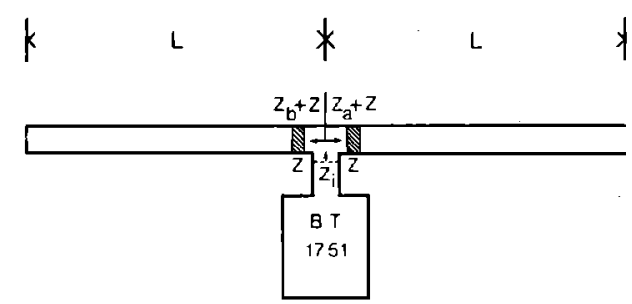

$Z_{a}=Z_{b} \Rightarrow Z_{i}=\left(Z_{a}+Z\right) \|\left(Z_{b}+Z\right)$ purely resistive

(b)

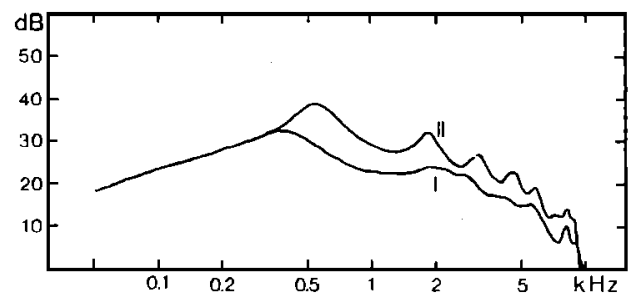

FIG. 1. (a) Schematic representation of probe microphone. (b) Pressure response of the probe microphone with (I) and without (II) compensation system.
In this system, a closed tube is used to compensate for the imaginary part of the impedance as seen from the microphone, utilizing the fact that the impedance of an open tube is the complex conjugate of the impedance of a closed tube of equal length (lossless case).

In this microphone, a transmission line compensator from a commercial hearing aid is used in combination with a hearing aid electret microphone (Knowles BT 1751). The microphone and the compensation network are built into a hearing aid case also containing the battery. This offers easy placement behind the earlobe.

As the damping resistors are placed inside the compensator, changing the tubing poses no problems. Another feature of this system is the ease with which different probes can be made with the same frequency response. The sensitivity of the microphone is $3 \mathrm{mV} / \mathrm{Pa}$ at $1 \mathrm{kHz}$.

II. MEASUREMENTS WITH THE PROBE MICROPHONE

A probe microphone as described is especially suited for investigating the acoustics of the outer ear and the ear canal. As an example is shown some measurements of the transfer characteristics of the ear canal as a function of direction to the sound source. Further measurements with this probe microphone will be described in a later paper.

The placing of the probe tube in the ear canal poses no problems, as it is too soft to rupture the eardrum, and it is simply pushed into the ear canal until it is felt

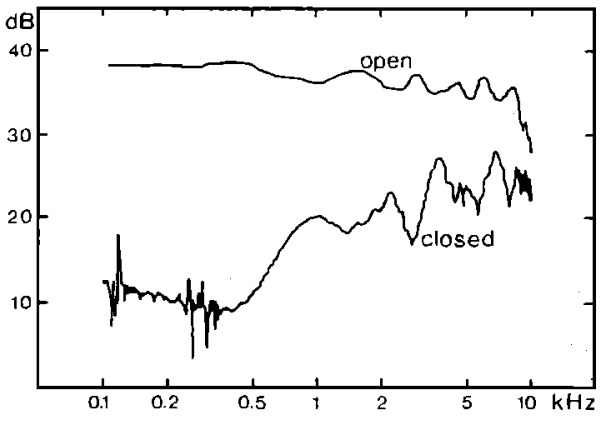

FIG. 2. Output from the probe microphone in open and closed condition. The surrounding sound field was regulated to give constant output from a similar probe mierophone in the open condition. 


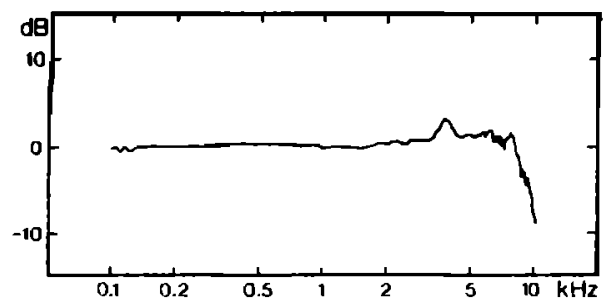

FIG. 3. Difference between the two probe microphones used, measured in free fleld with the probe tubes taped together.

touching the eardrum. It is then drawn out a bit so that it does not touch the eardrum during the measurement. It is, however, a good idea to mark the probe tube approximately $25 \mathrm{~mm}$ from the tip, as a guide for the placing of the tube.

\section{MEASURING METHOD}

The measuring method employed is based on the high reproducibility of the frequency response of different probe microphones. It is thus possible to measure the transfer characteristic from one point to another by placing the tips of two probe microphones at the relevant places and simply subtract the outputs. The precision with which this can be accomplished is indicated in Fig. 3.

As can be seen from Fig. 3, the response of the probe microphones is within $3 \mathrm{~dB}$ of each other in the frequency range $70 \mathrm{~Hz}$ to $10 \mathrm{kHz}$, corresponding to the usable frequency range of the microphones.

For measuring the transfer characteristic of the ear canal, the tip of one of the probe microphones was placed near the eardrum. The tip of the other was placed a short way into the ear canal, and the two tubes were taped together. The distance between the two probe tips were $23.5 \mathrm{~mm}$.

\section{RESULTS}

Measurements were taken for sound sources placed in the median and the transversal plane. In both cases, measurements were taken for sound sources spaced $30^{\circ}$, starting and ending in the horizontal plane. Results for the transversal plane are shown in Fig. 4.

The different transfer characteristics with respect to the direction simply reflect the fact that the pinna and

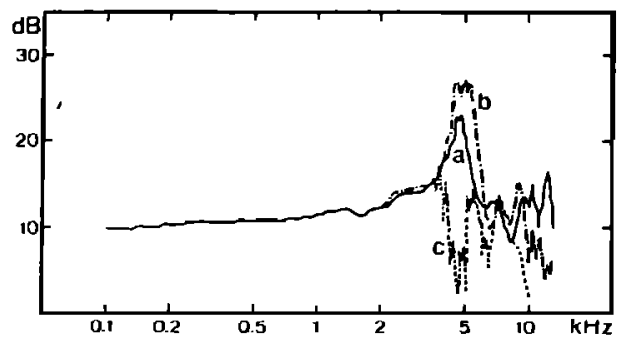

FIG. 4. Transfer function between two points spaced $23.5 \mathrm{~mm}$ In the right ear canal for the sound coming from various directions in the transversal plane: (a) From the right, (b) from above, and (e) from the left.

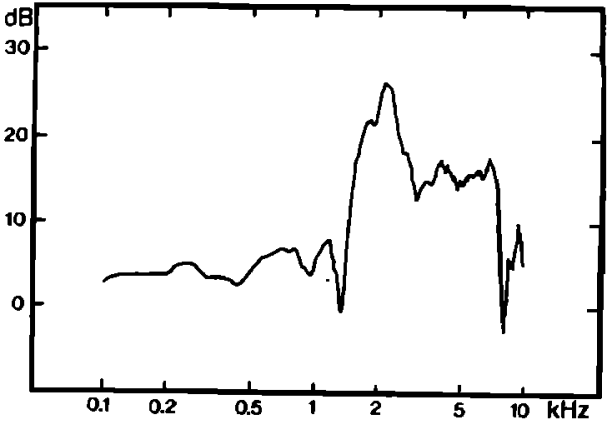

FIG. 5. Transfer function from free fleld to eardrum with the sound coming from directly ahead.

the ear canal together are responsible for the directional characteristics of the outer ear. Thus the ear canal cannot be regarded as an independent transmission line because the pressure transfer ratio between two points is not constant.

Another example of the use of these probe microphones is shown in Fig. 5, which shows the transfer characteristic from free field to the eardrum with the sound coming directly from ahead.

\section{MEASUREMENTS IN A CLOSED EAR CANAL}

For measurements of eardrum SPL, when an individually cast earmold is used, the flexible probe tube is indispensable. It can be inserted through an additional canal which only needs to be $1.7 \mathrm{~mm}$ wide and can have a curved course. Some examples are shown in Fig. 6.

To investigate the influence of the probe position in the closed ear canal, the following experiment was carried out.

The earmold was placed in the reference plane of a Zwislocki-coupler. A hearing aid output system was used to keep a constant sound pressure as measured by the microphone in the bottom of the coupler. The output from the probe microphone was measured with the probe tip in the reference plane and in the ear drum position. The results from the experiment are shown in Fig. 7.

As can be seen from this experiment, it is not necessary to insert the probe tip to the eardrum when measuring in the closed ear canal. A simple correction rising $6 \mathrm{~dB}$ per octave above $3 \mathrm{kHz}$ will compensate for the error when measuring at the reference plane instead of measuring at the eardrum.

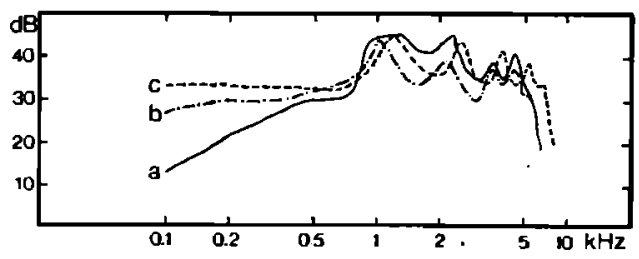

FIG. 6. Response of a hearing aid output system on two different subjects (curves $a$ and $b$ ). The response obtained in a Zwislock-coupler 1s shown for comparison (curve c). 


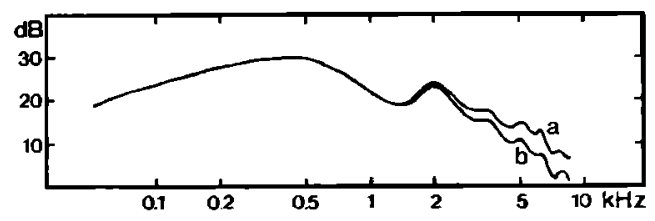

FIG. 7. Responge of the probe microphone in a Zwislockcoupler measured at the eardrum position (a) and at the reference plane (b).

\section{CONCLUSIONS}

It has been demonstrated that it is possible to build a probe microphone which is especially suited for investigating the acoustics of the outer ear.

As an example of possible use, the transfer characteristic of the human ear canal has been shown as a function of direction to the sound source, and it is shown that a transfer characteristic of the ear canal per se cannot be defined. Thus, in investigating the transformation from free field to the human eardrum, it is not permissible to measure the response at some point a little way into the ear canal and then apply the same correction to all measurements. In all cases, the response must be measured at the eardrum.

As indicated in Fig. 5, the transfer characteristic from free field to the eardrum is very complicated, and moreover, it is strongly dependent on direction of incidence. In a psychoacoustical experiment involving threshold measurements in the free field, the results will thus be strongly dependent on direction of Incidence, and the free field must be considered a bad reference for such measurements, unless all measurements are referred to eardrum sound pressure.

On the other hand, for the closed ear canal, it is not necessary to measure at the eardrum because the transfer function from the reference plane to the eardrum can be easily compensated for. This holds at least for frequencies below about 10 to $12 \mathrm{kHz}$, which is the upper limit for the microphones used.

Other possible applications of these probe microphones are measurements under earphones, either at the eardrum or in the concha, to get the true response of the earphones.

Finally, a word of caution. While the probe tube cannot harm a healthy ear, this might not be true in pathological cases.

\section{ACKNOWLEDGMENTS}

The probe microphones described here were developed by Ole Lauridsen, while he was at the Widex Corporation. The measurements with the probe microphones were carried out at the Acoustics Laboratory, Technical University of Denmark.

'Anon., Brïel and Kjær Instruction Manual for Probe Microphone Type 4170 (Brüel and Kjær, Nærum, Denmark, 1974). ${ }^{2}$ E. V. Carlson, "Smoothing the Hearing Aid Frequency Response," J. Aud. Eng. Soc. 22 (6), 426-429 (1974). 